\title{
Introduction-Knowledge Translation and Urban Health Equity: Advancing the Agenda
}

\author{
Kelly Murphy, Patrick Fafard, and Patricia O'Campo
}

\begin{abstract}
In 2011, an interdisciplinary symposium was organized in Toronto, Canada to investigate prevailing models of health policy change in the knowledge translation literature and to assess the applicability of these models for equity-focused urban health research. The papers resulting from the symposium have been published together, in the Journal of Urban Health, along with this introductory essay. This essay describes how the different papers grapple in different ways with how to understand and to bridge the gaps between urban health research and action. The breadth of perspectives reflected in the papers (e.g., social epidemiology, public health, political science, sociology, critical labor studies, and educational psychology) shed much light on core tensions in the relationship between KT and health equity. The first tension is whether the content of evidence or the context of decision making is the strong determinate of research impact in relation to health equity policy. The second tension is whether relationships between health equity researchers and decision makers are best viewed in terms of collaboration or of conflict. The third concerns the role that power plays in evidence-based policy making, when the issues at stake are not only empirical but also normative.
\end{abstract}

KEYWORDS Urban health, Knowledge translation, Power, Politics, Policy change, Evidence-based decision making, Health equity

\section{INTRODUCTION}

Health equity research illuminates the uneven effects on population health of diffuse social and health policy choices made by multiple sectors and orders of government, diverse decision makers and other influential actors. Cities, particularly inner city areas, are the geographical and social containers where many of the most deleterious health inequities become visible. ${ }^{1}$ For example, much has been made of the observation made in the Report of the World Health Organization Commission on the Social Determinants of Health that residents of a poor area of Glasgow, Scotland have a very low life expectancy, 30 years less than in a nearby prosperous

\footnotetext{
Murphy is with the Li Ka Shing Knowledge Institute in the Keenan Research Centre of St. Michael's Hospital, Toronto, ON, Canada; Fafard is with the University of Ottawa, Ottawa, ON, Canada; O'Campo is with the Alma and Baxter Ricard Chair in Inner City Health, Toronto, ON, Canada; O'Campo is with the Centre for Research on Inner City Health, Toronto, ON, Canada; O'Campo is with the Dalla Lana School of Public Health, University of Toronto, Toronto, ON, Canada; O'Campo is with the Johns Hopkins Bloomberg School of Public Health, Baltimore, MD, USA.

Correspondence: Kelly Murphy, Li Ka Shing Knowledge Institute in the Keenan Research Centre of St. Michael's Hospital, Toronto, ON, Canada. (E-mail: MurphyKe@smh.ca)
} 
area, and even less than in poor areas in India. ${ }^{2}$ Cities are also settings where evidence-based, intersectoral policy solutions are urgently needed to address health problems and the social determinants of health, including homelessness, poverty and job insecurity, youth violence, environmental risks, racism, and newcomer isolation. ${ }^{3}$

The persistence of urban health inequalities begs the questions of when and why actions are (or are not) taken to address them. What triggers decisive policy action to reduce the unequal burdens of disability and disease as well as their social determinants? One way of approaching these questions is to examine the influence of research evidence in prompting progressive social policy and health system changes to improve health equity. This gives rise to a focus on knowledge translation (KT), a growing movement in research communities aimed to help make health research more relevant and useful, ${ }^{4}$ and to move research into practice and policy. ${ }^{5,6}$

The World Health Organization defines KT as "the synthesis, exchange, and application of knowledge by relevant stakeholders to accelerate the benefits of global and local innovation in strengthening health systems and improving people's health". ${ }^{7}$ KT frameworks for health are premised on perceived structural and/or cultural gaps between the individuals and organizations responsible for managing health systems and delivering health care, on the one hand, and those responsible for conducting health research, on the other. The KT view is that scientific publication in peer-reviewed journals is too passive a research dissemination practice to produce tangible and timely impacts on health policy making, programming, and practice. Instead, KT encourages research personnel to actively: (1) interact and collaborate with the relevant decision makers throughout the research process, to ensure the research project explores aspects of the problem and potential solutions that matter for decision making; (2) explain the research results to the relevant decision makers in terms that are meaningful, actionable, and that help the decision makers to solve their problem; and (3) present research results in formats that are easily accessible to the relevant decision makers. These strategies obviously do not guarantee that research will have an influence on policy or practice, nonetheless KT has been broadly viewed as a major advance toward this goal because it encourages greater intentionality on the part of the research community in establishing appropriate preconditions (e.g., relevance, accessibility, actionability, and stakeholder capacity to use research) to support research uptake. ${ }^{8}$

At least on the surface, therefore, KT appears to offer very promising strategies for accelerating the uptake of research evidence to practically reduce urban health inequities. However, most KT models and best practices have been generated primarily for clinical and single-sector health care decision-making contexts and are rooted in evidence-based medicine. These models tend to be silent on the complexities of cross-sectoral, multilevel policy change and the implications of these complexities for evidence creation about social determinants of health. They also have little to say about the influence of power, politics, and social movements in shaping health inequities. These absences affect the extent to which KT approaches can increase the impact of urban health research on urban health policies.

In 2011, an interdisciplinary symposium of KT, policy studies, and urban health experts was organized in Toronto, Canada, to investigate the prevailing models of health policy change proposed in the KT literature and to assess their applicability for equity-focused urban health research. The papers prepared for the symposium, several of which are published here, grappled in different ways with the problems of 
how to understand the gaps between urban health research and action-and how to bridge these gaps. The breadth of perspectives reflected in the papers, achieved in part through the diverse disciplinary backgrounds of the authors (e.g., social epidemiology, public health, political science, sociology, critical labor studies, and educational psychology), shed much light on core tensions in the relationship between KT and health equity. The first tension is whether the content of evidence or the context of decision making is the strong determinate of research impact in relation to health equity policy. The second tension is whether relationships between health equity researchers and decision makers are best viewed in terms of collaboration or of conflict. The third concerns the role that power plays in evidence-based policy making, and highlights how health inequities are not only empirical but also normative problems to solve.

\section{WHAT MATTERS MOST FOR HEALTH EQUITY KT? WEIGHING THE CONTENT OF EVIDENCE AND THE CONTEXT OF DECISION MAKING}

One way of conceiving of the papers collected here is to note that in some, the primary KT focus is on the "evidence" side of evidence-based decision making, while others emphasize "decision making". The authors interested in "evidence" question whether or not the urban health research community is actually producing the kind of knowledge that can be mobilized through KT strategies to inform policy action. For example, O'Campo calls for less research devoted to describing inequities that we already know about, ${ }^{9}$ and for more research aimed at finding solutions to these problems; particularly solutions that target the macro social determinants of health. Martens shows that the methods researchers employ to analyze and present health equity data ${ }^{10}$ can have a pronounced effect on policymakers' motivation and responsibility to act on the findings. Wallace's paper argues for balancing fidelity requirements with options for adapting evidencebased $^{11}$ programs to local conditions. What these papers share in common is the view that evidence-based interventions for health equity can be impeded by the research community itself when it fails to take seriously the evidence needs and research uptake capacity ${ }^{8}$ of policy and program stakeholders. From this perspective, greater intentionality on the part of researchers, at every stage of the research process, to produce evidence that is useful and relevant is a necessary precondition for effective KT for health equity. As we shall see below, this perspective also encourages greater collaboration and communication between health equity researchers and potential stakeholders (sometimes called, "integrated

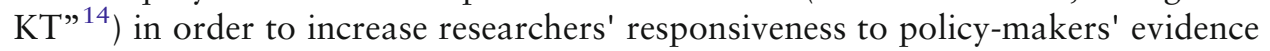
"needs".

Other papers in the collection emphasize the context of decision making itself as the real determinant of research impact on policy making. These papers suggest the need for more sophisticated "policy literacy" on the part of urban health researchers, in order to become more strategic and ultimately effective in our efforts to bring evidence to bear on policy change. This means developing better understanding of the specific levers of influence that matter for the issues and the contexts that we are studying. Fafard, for example, shows how robust judicial mechanisms combined with many years ${ }^{15}$ of political struggle secured the Government of Canada's continued support for INSITE, the safe injection facility in Vancouver, Canada. The amassing of high-quality, solutions-focused evidence, 
was insufficient. In their paper, Murphy and Fafard also prioritize the decisionmaking context. By bringing forward concepts from policy ${ }^{16}$ studies to supplement the traditionally narrow KT account of decision making, they identify a broader array of policy change entry points and target audiences for health equity research evidence. Muntaner et al. also argue that what matters for health equity research utilization is not simply the strength ${ }^{17}$ of the evidence but its goodness of fit with the political ideology of the governing party, and whether or not "policy windows" 18 are open enough for decision makers to receive research evidence. These papers call for greater intentionality within the research community, in terms of how we frame and time the delivery our evidence-based messages about urban health issues, in relation to the decision-making context.

\section{COLLABORATIONS OR CONFLICTS BETWEEN RESEARCHERS AND DECISION MAKERS}

Knowledge translation models tend to place an extremely high premium on the quality of relationships between researchers and decision makers. Closer relationships are expected to foster, on the one hand, better understanding among researchers about the evidence needs and policy priorities of decision makers, and on the other hand, better scientific literacy and capacity to use research among decision makers. ${ }^{19}$ As they reflect on the relevance of KT models for health equity research and policy making, the authors of these papers bring diverse perspectives about feasible and appropriate relationships between researchers and decision-makers. The paper by Martens, ${ }^{10}$ for example, describes how progressive advances in both research and policy can be made through carefully structured and collegial partnerships between researchers and governments, in this case in the Canadian province of Manitoba. This work demonstrates the successful application of a KT linkage and exchange ${ }^{20}$ model to bridge health equity research and policy. Like Martens, O'Campo ${ }^{9}$ sees opportunities for genuine collaboration and co-creation of knowledge between autonomous practitioners and researchers acting in concert. Wallace, ${ }^{11}$ on the other hand, is sceptical of research-policy collaborations for urban health, pointing to governments' continued support for the war on drugs, in spite of mounting evidence about the health and social effectiveness of harm reduction approaches. The limits to genuine collaboration between researchers and decision makers are also important for Muntaner et al. ${ }^{17}$ and are discussed in the paper by Murphy and Fafard ${ }^{16}$, who use a discourse analysis approach to show why researcher/decision maker relationships may in fact be highly undesirable to both parties, particularly if their definitions of the policy problem are conflicting.

\section{POWER/KNOWLEDGE AND KT FOR HEALTH EQUITY}

The third tension that emerges when KT is applied to health equity is about power. How do politics and power affect opportunities for evidence-based policy when the issues at stake are not only empirical but also normative, as in the case of health equity research, which is usually anchored in a social justice framework? Conventional KT models, which have been designed to support essentially technical-instrumental decisions, assume a pluralist perspective when it comes to policy making. ${ }^{21}$ Pluralism here refers to a particular conception of the distribution of power in society and the 
effects of that distribution on how government operates. Power, on the pluralist view, is widely distributed, the policy process is relatively open, and what governments do or do not do is the result of a complex process of sorting and objectively resolving conflicting and competing claims. ${ }^{22}$ In their papers, Martens and O'Campo both implicitly assume a pluralist model of government, wherein decision makers will be open to the use of research evidence if it is, relevant (in the case of Martens), and helps to solve problems (in the case of O'Campo). The alternative perspective, suggested by Wallace and by Murphy and Fafard, and reflected most clearly through the social conflict lens of Muntaner et al., is that power concentrates in the hands of elite groups. This concentration of power enables them to control access to the policy process (Muntaner et. al.) and to define what counts as policy problem and a feasible solution (Fafard, Wallace, Murphy, and Fafard). On this view, the health equity researcher's ability to contribute evidence to the policy process may depend less on the quality of the evidence, and more on the ideological interests of powerful groups. While scientific evidence can inform technical decisions, these papers suggest, it does not drive normative ones.

How best to connect science and progressive social change is an increasingly important theme in many academic disciplines. ${ }^{13,16,23}$ The authors of the papers collected here show how the urban health research community can draw on the ongoing efforts in these other disciplines to work through such complex KT challenges. In sum, these papers suggest an exciting and complex agenda for urban health researchers, that will foster greater intentionality and deliberateness in relation to both our policy change goals, and our diverse research roles.

\section{ACKNOWLEDGMENTS}

This work has been funded in part by the Canadian Institutes of Health Research (CIHR) under grant no. 101693, entitled "Power, Politics, and the Use of Health Equity Research”.

\section{REFERENCES}

1. Vlahov D, Bouffard JI, Pearson CE, Norris N, eds. Urban health: global perspectives. San Francisco: Jossey-Bass; 2010.

2. Marmot M. Achieving health equity: from root causes to fair outcomes. The Lancet. 2007; 370(9593): 1153-1163.

3. Bayoumi AM, Hwang SW. Methodological, practical, and ethical challenges to inner-city health research. J Urban Health. 2002; 79(4 Suppl 1): S35-S42.

4. Green LW, Glasgow RE, Atkins D, Stange K. Making evidence from research more relevant, useful, and actionable in policy, program planning, and practice: slips "twixt cup and lip". Am J Prev Med. 2009; 37(6S1). doi:10.1016/j.amepre.2009.08.017.

5. Lomas J. Using 'linkage and exchange' to move research into policy at a Canadian foundation. Health Aff. 2000; 19(3): 236-240.

6. National Institutes of Health. National Centre for Clinical Research Resources. Clinical and Translational Science Awards Fact Sheet. Summer 2011. https:// www.ctsacentral.org/documents/Communication_Toolkit/CTSA_FactSheet.pdf. Accessed 19 December 2011

7. World Health Organization. Bridging the "know-do" gap: meeting on knowledge translation in global health. Geneva, Switzerland: WHO; 2005. 
8. Pentland D, Forsyth K, Maciver D, Walsh M, Murray R, Irvine L, et al. Key characteristics of knowledge transfer and exchange in healthcare: integrative literature review. J Adv Nurs. 2011; 67(7): 1408-1425. doi:10.1111/j.1365-2648.2011.05631.x. Epub 2011 Apr 6.

9. O'Campo P. Are We Producing the Right Kind of Actionable Evidence for the Social Determinants of Health? J Urban Health. 2012; doi:10.1007/s11524-012-9695-5.

10. Martens PJ. The Right Kind of Evidence-Integrating, Measuring, and Making It Count in Health Equity Research. J Urban Health. 2012; doi:10.1007/s11524-012-9696-4.

11. Wallace BC. Controversies in Knowledge Translation for Community-Based Drug Treatment: The Need to the End Policies of the War on Drugs and Mass Incarceration of Drug Offenders to Achieve Health Equity. J Urban Health. 2012; doi:10.1007/s11524012-9697-3.

12. O’Campo P, Dunn JR. Introduction. In: O'Campo P, Dunn JR, eds. Rethinking Social Epidemiology. Dordrecht: Springer Netherlands; 2012:1-19. http://www.springerlink. com/content/m5w62523642241p3. Accessed December 20, 2011.

13. Burawoy M. For Public Sociology. Am Sociol Rev. 2005; 70(1): 4-28.

14. Gagnon ML. Moving knowledge to action through dissemination and exchange. J Clin Epidemiol; 2009.

15. Fafard P. Public Health Understandings of Policy and Power: Lessons from INSITE. J Urban Health. 2012; doi:10.1007/s11524-012-9698-2

16. Murphy K, Fafard P. Taking Power, Politics, and Policy Problems Seriously. J Urban Health. 2012; doi:10.1007/s11524-012-9694-6.

17. Muntaner C, Chung H, Murphy K, Ng E. Barriers to Knowledge Production, Knowledge Translation, and Urban Health Policy Change: Ideological, Economic, and Political Considerations. J Urban Health. 2012; doi:10.1007/s11524-012-9699-1.

18. Kingdon JW. Agendas, alternatives, and public policies. New York: Longman; 2003.

19. Best A, Hiatt RA, Norman CD. Knowledge integration: conceptualizing communications in cancer control systems. Patient Educ Couns. 2008; 71(3): 319-327.

20. Lomas, J. Using 'linkage and exchange' to move research into policy at a Canadian foundation. Health Affairs. 2000; 19(3): 236-240.

21. Monaghan M. Evidence versus politics: exploiting research in UK drug policy making? Bristol: Policy Press; 2011.

22. Dahl R. Who governs? Democracy and power in the American city. New Haven, CT: Yale University Press; 1963.

23. Eisfeld R. How political science might regain relevance and obtain an audience: a manifesto for the 21st century. Eur Polit Sci. 2011; 10(2): 220-225. 